\title{
Role of Road Connectivity in Socio-Economic Development of Shrirampur Tehsil of Ahmednagar District (Maharashtra)
}

\author{
Sandip Sasane ${ }^{1}$, Nanasaheb Shelke ${ }^{2}$ \\ ${ }^{1}$ Assistant Professor, Department of Geography, R. B. N. B. College, Shrirampur \\ ${ }^{2}$ Assistant Professor, Department of Geography, Ahmednagar College, Ahmednagar
}

\begin{abstract}
The transport is playing a vital in socio-economic development of rural areas hence the attempted has been made to find out the role of road connectivity in socio-economic development in Shrirampur tehsil. The road network map was prepared on basic of Google map; Connectivity Composite Score was calculated with the help of Beta Index and Cyclomatic Index. Here lower the CCS value, higher the connectivity and vice versa. Therefore high connectivity villages are Shrirampur(2), Taklibhan(6), Belapur Bk.(8), Haregaon(10), Padhegaon(15) and Shirasgaon(18) etc. while low connectivity found in the villages, Eklahare(107), Gurjarwadi (107), Naygaon (107), Rampur(107), and Wangi(106.5) etc. After that Socio-Economic Development Composite Score was also calculated using population density, Sex Ratio, Literacy Rate, Share of worker to total population and NSA's Rank Orders. Here lower the composite score value, higher the socio-economic development and vice versa. Therefore high socio-economic development villages are Kadit Kh (64), Narsari (81), Kadit bk (92.5), Matapur (97) and Muthewadgaon (99.5) etc. whereas low socio-econominc development found in the villages, Wangi (237.5), Bhamathan \& Nipaniwadgaon (193), Kamalpur (190.5), Khokar (186.5) and Naur (183.5) etc. The correlation coefficient ( $r$ value) between road connectivity and socio-economic development is 0.01 which indicates very weak correlation between road connectivity and socio-economic development in Shrirampur tahsil.
\end{abstract}

Keywords: Beta Index, Cyclomatic Index, Connectivity, Socio-economic Development, Correlation

\section{Introduction}

The transport is playing a vital role in development of any region, basically, transport network is regarded as a set of an interconnected route linking of numerous destinations within and outside the region and provide a pace for movement to people and commodities. It real sense, it serves manifold functions for regional development. The relation between transport and economic or regional development is a matter of practical as well as theoretical importance and one that has received considerable attention over many years in both advanced and developing countries. The geographer is more concerned with spatial implications of such developments and their impact upon the activities in a particular region. Geographical study of transportation and its relationship with socio-economic development is an important and developing field of research. Transport network is a set of geographic locations inter connected in a system by a number of routs (Kansky, 1963) whereas the connectivity of a network is the degree of completeness of links between nodes', (Robinson \& Bamford, 1978). Some scholars has been attempted to find out correlation between connectivity and development such as Saxena H. M. (1980) had try to find out correlation of connectivity with development in all districts of Rajasthan State. Sadhana H. Bhendkar (1985) she attempted to examined road connectivity for Vidarbha in Maharashtra. R. V. Vinod et all. (2003) study transport network of roads and railways in Kasaragod taluk, Kasaragod district of Kerala and found that the coastal area is well connected with road network and the eastern hilly region has poor connectivity and accessibility. Therefore attempt has been made to study the correlation between road connectivity and socio-economic development in Shrirampur tehsil

\section{Study Area}

Shrirampur Tahsil is located in the North part of Ahmednagar district of Maharashtra state and is extended between $19^{\circ} 45$ to $20^{\circ} 30 \mathrm{~N}$ latitudes and $74^{\circ} 00$ to $74^{\circ} 30 \mathrm{E}$ longitudes. The total geographical area of the tahsil is $579.87 \mathrm{sq} . \mathrm{km}$ which covers 54 villages. The net cultivated area in 2006-07 was $480 \mathrm{sq}$. km. About $70 \%$ of the area is irrigated by canal and dug wells, putting high pressure on groundwater resources of the Tahsil. The total population of tahsil is 2, 56,441 (Census, 2001) and almost $80 \%$ of the workforce is engage in the agriculture, horticulture, animal husbandry and Sugar Industries. The Tahsil has a subtropical monsoon climate. March, April, and May are the hottest months while December and January are the coldest. The maximum temperature recorded during summers is about $44^{\circ} \mathrm{C}$ and it is as low as $8^{\circ} \mathrm{C}$ in winters. The Tahsil receives an approximate average rainfall of $550 \mathrm{~mm}$ and more than $75 \%$ of which occurs during the monsoon period (July-September).

\section{Methodology}

The present study is based on secondary data. The secondary of data was obtained from socio-economic review and district census handbook. In present study edges and nodes are calculated on tahsil map with the help computer software and road transport connectivity has calculated by two indices, i.e. Beta index and Cyclomatic index. Composite Connectivity Score calculated give with Rank Order with the help of MS Excel and maps were prepared in Arc GIS 9.3 Software. 


\section{International Journal of Science and Research (IJSR) \\ ISSN (Online): 2319-7064 \\ Index Copernicus Value (2013): 6.14 | Impact Factor (2015): 6.391}

Socio-Economic Development Score also calculated using population density, Sex Ratio, Literacy Rate, Share of worker to total population and NSA's Rank Orders in MS Excel and maps were make using Arc GIS 9.3 Software.

Finally, Correlation between Road Connectivity and SocioEconomic Development was calculated applied with Karl Person Correlation method. Suggestions made for improving road connectivity in support of sustainable Socio-Economic Development.

\section{Results and Discussions}

Table 1: Village wise Rank of Connectivity of Shrirampur Tahsil

\begin{tabular}{|c|c|c|c|c|c|c|c|c|c|}
\hline $\begin{array}{l}\text { Sr. } \\
\text { No. }\end{array}$ & Village Name & $\begin{array}{l}\text { Beta } \\
\text { Index }\end{array}$ & $\begin{array}{c}\text { Cyclomatic } \\
\text { Index }\end{array}$ & $\begin{array}{c}\text { Total } \\
(\mathrm{CCS})\end{array}$ & Sr. No & Village Name & $\begin{array}{l}\text { Beta } \\
\text { Index }\end{array}$ & $\begin{array}{l}\text { Cyclomatic } \\
\text { Index }\end{array}$ & $\begin{array}{c}\text { Total } \\
\text { (CCS) }\end{array}$ \\
\hline 1 & Ainatpur & 43 & 45.5 & 88.5 & 29 & Kuranpur & 9.0 & 22.5 & 31.5 \\
\hline 2 & Belapur Bk & 2.0 & 6 & 8 & 30 & Ladgaon & 43.0 & 35 & 78 \\
\hline 3 & Belapur Kh & 21.5 & 35 & 56.5 & 31 & Mahankal Wadgaon & 30 & 22.5 & 52.5 \\
\hline 4 & Gondhavani & 6 & 9 & 14.5 & 32 & Malewadi & 30 & 22.5 & 52.5 \\
\hline 5 & Bhamathan & 22 & 35 & 56.5 & 33 & Malunje Bk & 43.0 & 22.5 & 65.5 \\
\hline 6 & Bherdapur & 22 & 35 & 56.5 & 34 & Malwadgaon & 30 & 15 & 45 \\
\hline 7 & Bhokar & 12.0 & 9 & 21 & 35 & Mandve & 30.0 & 15 & 45 \\
\hline 8 & Bramhangaon Vetal & 43.0 & 52.5 & 95.5 & 36 & Matapur & 9.0 & 22.5 & 31.5 \\
\hline 9 & Dattanagar & 43.0 & 52.5 & 95.5 & 37 & Matulthan & 22 & 35 & 56.5 \\
\hline 10 & Dighi & 43.0 & 35 & 78 & 38 & Muthewadgao & 22 & 11.5 & 33 \\
\hline 11 & Ekalahare & 54.0 & 52.5 & 106.5 & 39 & Narsari & 43 & 45.5 & 88.5 \\
\hline 12 & Fatyabad & 43.0 & 35 & 78 & 40 & Naur & 22 & 35 & 56.5 \\
\hline 13 & Galnimb & 43.0 & 35 & 78 & 41 & Naygaon & 54.0 & 52.5 & 106.5 \\
\hline 14 & Ghumandeo & 21.5 & 35 & 56.5 & 42 & Nimgaon Khairi & 9.0 & 11.5 & 20.5 \\
\hline 15 & Gondegaon & 13.5 & 15 & 28.5 & 43 & Nipani Wadgaon & 9 & 22.5 & 31.5 \\
\hline 16 & Govardhanpur & 43.0 & 35 & 78 & 44 & Padhegaon & 9.0 & 6 & 15 \\
\hline 17 & Gurjarwadi & 54.0 & 52.5 & 106.5 & 45 & Rampur & 54.0 & 52.5 & 106.5 \\
\hline 18 & Haregaon & 5.5 & 4 & 9.5 & 46 & Sarala & 21.5 & 35 & 56.5 \\
\hline 19 & Jafrabad & 43.0 & 45.5 & 88.5 & 47 & Shirasgaon & 3.0 & 15 & 18 \\
\hline 20 & Kadit Bk & 43 & 45.5 & 88.5 & 48 & Takalibhan & 4.0 & 2 & 6 \\
\hline 21 & Kadit Kh & 22 & 35 & 56.5 & 49 & Ukkalgaon & 43.0 & 22.5 & 65.5 \\
\hline 22 & Kamalpur & 13.5 & 15 & 28.5 & 50 & Umbargaon & 30 & 22.5 & 52.5 \\
\hline 23 & Kanhegaon & 43.0 & 52.5 & 95.5 & 51 & Undirgaon & 15.5 & 3 & 18.5 \\
\hline 24 & Karegaon & 15.5 & 6 & 21.5 & 52 & Wadala Mahadeo & 34.0 & 9 & 43 \\
\hline 25 & Khanapur & 30.0 & 22.5 & 52.5 & 53 & Waladgaon & 43.0 & 45.5 & 88.5 \\
\hline 26 & Khandala & 22 & 35 & 56.5 & 54 & Wangi & 54 & 52.5 & 106.5 \\
\hline 27 & Khirdi & 43.0 & 35 & 78 & 55 & Wangi Kh & 43 & 45.5 & 88.5 \\
\hline 28 & Khokar & 30.0 & 22.5 & 52.5 & 56 & Shrirampur & 1.0 & 1 & 2 \\
\hline
\end{tabular}

The levels of Socio-Economic development can be determined by different socio-economic parameters, population density, Sex Ratio, Literacy Rate, workers of Total population (\%), Net Sown Area (\%) etc. All the 56 villages have been ranked separately for each variable
Transport is plays a vital role in socio-economic development of area, road types, mode of transports, connectivity, frequency and traffic flows etc. are key elements in transport system. Therefore attempted has been made to analysis the role of road connectivity in socioeconomic development of Shrirampur tehsil. Road network was prepared with Beta Index and Cyclomatic Index. Beta Index is expressed by the relationship between the number of links (edges) over cycle has a value of 1 . More complex networks have a value greater than 1 in a network with a fixed number of nodes. Complex network have a high beta index. The connectivity values obtained through Beta Index in Shrirampur tahsil varies from 2 to 6 . While Cyclomatic Index is also one of the good measures of connectivity, higher the index value, higher the connectivity (Table 1).
(Source: Computed by Researcher) according to their levels of development. Thus every village has five rank values. The composite connectivity scores (CCS) have been computed by adding respective ranks of all socio-economic parameters (Table 2). 


\section{International Journal of Science and Research (IJSR) ISSN (Online): 2319-7064}

Index Copernicus Value (2013): 6.14 | Impact Factor (2015): 6.391

Table 2: Village wise rank of Socio-Economic Development

\begin{tabular}{|c|c|c|c|c|c|c|c|}
\hline $\begin{array}{l}\text { Sr. } \\
\text { No. }\end{array}$ & Village Name & $\begin{array}{c}\text { Population } \\
\text { Density }\end{array}$ & $\begin{array}{c}\text { Sex } \\
\text { Ratio } \\
\end{array}$ & \begin{tabular}{|l|} 
Literacy \\
Rate $(\%)$ \\
\end{tabular} & $\begin{array}{l}\text { Workers of Total } \\
\text { Population }(\%)\end{array}$ & $\begin{array}{c}\text { Net Sown to } \\
\text { Total Area }(\%)\end{array}$ & $\begin{array}{c}\text { Composite } \\
\text { Scores }\end{array}$ \\
\hline 1 & Ainatpur & 3 & 14 & 27.5 & 53 & 16.5 & 114.0 \\
\hline 2 & Belapur Bk & 5 & 12.5 & 17.5 & 51 & 27.0 & 113.0 \\
\hline 3 & Belapur Kh & 9 & 37 & 3 & 41 & 33.5 & 123.5 \\
\hline 4 & Gondhavani & 11 & 9 & 35.5 & 45.5 & 39.0 & 140.0 \\
\hline 5 & Bhamathan & 51 & 45 & 45.5 & 20.5 & 31.0 & 193.0 \\
\hline 6 & Bherdapur & 37 & 20 & 45.5 & 28 & 38.0 & 168.5 \\
\hline 7 & Bhokar & 32 & 21 & 35.5 & 20.5 & 51.0 & 160.0 \\
\hline 8 & Bramhangaon Vetal & 14 & 41 & 27.5 & 28 & 7.5 & 118.0 \\
\hline 9 & Dattanagar & 2 & 9 & 4.5 & 49 & 53.0 & 117.5 \\
\hline 10 & Dighi & 45 & 6 & 27.5 & 32 & 29.5 & 140.0 \\
\hline 11 & Ekalahare & 6 & 31 & 53 & 54 & 4.0 & 148.0 \\
\hline 12 & Fatyabad & 10 & 15.5 & 12.5 & 6 & 41.5 & 85.5 \\
\hline 13 & Galnimb & 48 & 3 & 38.5 & 24.5 & 54.0 & 168.0 \\
\hline 14 & Ghumandeo & 33 & 17.5 & 45.5 & 49 & 2.0 & 147.0 \\
\hline 15 & Gondegaon & 21 & 46.5 & 12.5 & 12 & 11.0 & 103.0 \\
\hline 16 & Govardhanpur & 55 & 34 & 45.5 & 4 & 29.5 & 168.0 \\
\hline 17 & Gurjarwadi & 25 & 27 & 56 & 24.5 & 27.0 & 159.5 \\
\hline 18 & Haregaon & 46 & 3 & 35.5 & 38 & 55.0 & $\mathbf{1 7 7 . 5}$ \\
\hline 19 & Jafrabad & 47 & 22 & 55 & 38 & 9.5 & 171.5 \\
\hline 20 & Kadit Bk & 13 & 49 & 22 & 3 & 5.5 & 92.5 \\
\hline 21 & Kadit Kh & 39 & 15.5 & 7.5 & 1 & 1.0 & 64.0 \\
\hline 22 & Kamalpur & 52.5 & 56 & 7.5 & 56 & 18.5 & 190.5 \\
\hline 23 & Kanhegaon & 31 & 24 & 22 & 41 & 16.5 & 134.5 \\
\hline 24 & Karegaon & 36 & 28 & 35.5 & 12 & 48.5 & 160.0 \\
\hline 25 & Khanapur & 43 & 41 & 42 & 9.5 & 7.5 & 143.0 \\
\hline 26 & Khandala & 24 & 7 & 35.5 & 17 & 27.0 & 110.5 \\
\hline 27 & Khirdi & 15 & 51.5 & 50.5 & 9.5 & 14.5 & 141.0 \\
\hline 28 & Khokar & 30 & 41 & 35.5 & 35 & 45.0 & 186.5 \\
\hline 29 & Kuranpur & 19 & 48 & 12.5 & 14.5 & 14.5 & 108.5 \\
\hline 30 & Ladgaon & 40.5 & 50 & 22 & 30 & 33.5 & 176.0 \\
\hline 31 & Mahankal Wadgaon & 52.5 & 51.5 & 42 & 6 & 24.5 & 176.5 \\
\hline 32 & Malewadi & 23 & 26 & 38.5 & 12 & 21.0 & 120.5 \\
\hline 33 & Malunje Bk & 18 & 1 & 50.5 & 20.5 & 22.0 & 112.0 \\
\hline 34 & Malwadgaon & 28 & 5 & 27.5 & 38 & 32.0 & 130.5 \\
\hline 35 & Mandve & 27 & 29 & 7.5 & 35 & 18.5 & 117.0 \\
\hline 36 & Matapur & 8 & 46.5 & 12.5 & 24.5 & 5.5 & 97.0 \\
\hline 37 & Matulthan & 50 & 53 & 48 & 6 & 12.0 & 169.0 \\
\hline 38 & Muthewadgaon & 17 & 32.5 & 12.5 & 24.5 & 13.0 & 99.5 \\
\hline 39 & Narsari & 29 & 32.5 & 2 & 8 & 9.5 & 81.0 \\
\hline 40 & Naur & 38 & 35 & 42 & 32 & 36.5 & 183.5 \\
\hline 41 & Naygaon & 54 & 19 & 38.5 & 17 & 44.0 & 172.5 \\
\hline 42 & Nimgaon Khairi & 34 & 11 & 7.5 & 20.5 & 47.0 & 120.0 \\
\hline 43 & Nipani Wadgaon & 4 & 55 & 50.5 & 35 & 48.5 & 193.0 \\
\hline 44 & Padhegaon & 12 & 12.5 & 22 & 45.5 & 40.0 & 132.0 \\
\hline 45 & Rampur & 40.5 & 23 & 50.5 & 32 & 3.0 & 149.0 \\
\hline 46 & Sarala & 56 & 44 & 12.5 & 2 & 43.0 & 157.5 \\
\hline 47 & Shirasgaon & 7 & 9 & 1 & 55 & 46.0 & 118.0 \\
\hline 48 & Takalibhan & 26 & 25 & 27.5 & 28 & 52.0 & 158.5 \\
\hline 49 & Ukkalgaon & 35 & 30 & 17.5 & 17 & 50.0 & 149.5 \\
\hline 50 & Umbargaon & 20 & 43 & 27.5 & 41 & 24.5 & 156.0 \\
\hline 51 & Undirgaon & 16 & 3 & 17.5 & 52 & 35.0 & 123.5 \\
\hline 52 & Wadala Mahadeo & 22 & 37 & 4.5 & 45.5 & 41.5 & 150.5 \\
\hline 53 & Waladgaon & 42 & 39 & 22 & 45.5 & 20.0 & 168.5 \\
\hline 54 & Wangi & 44 & 54 & 54 & 49 & 36.5 & 237.5 \\
\hline 55 & Wangi Kh & 49 & 37 & 38.5 & 14.5 & 23.0 & 162.0 \\
\hline 56 & Shrirampur & 1 & 17.5 & 17.5 & 43 & 56.0 & 135.0 \\
\hline
\end{tabular}




\section{International Journal of Science and Research (IJSR) \\ ISSN (Online): 2319-7064}

Index Copernicus Value (2013): 6.14 | Impact Factor (2015): 6.391

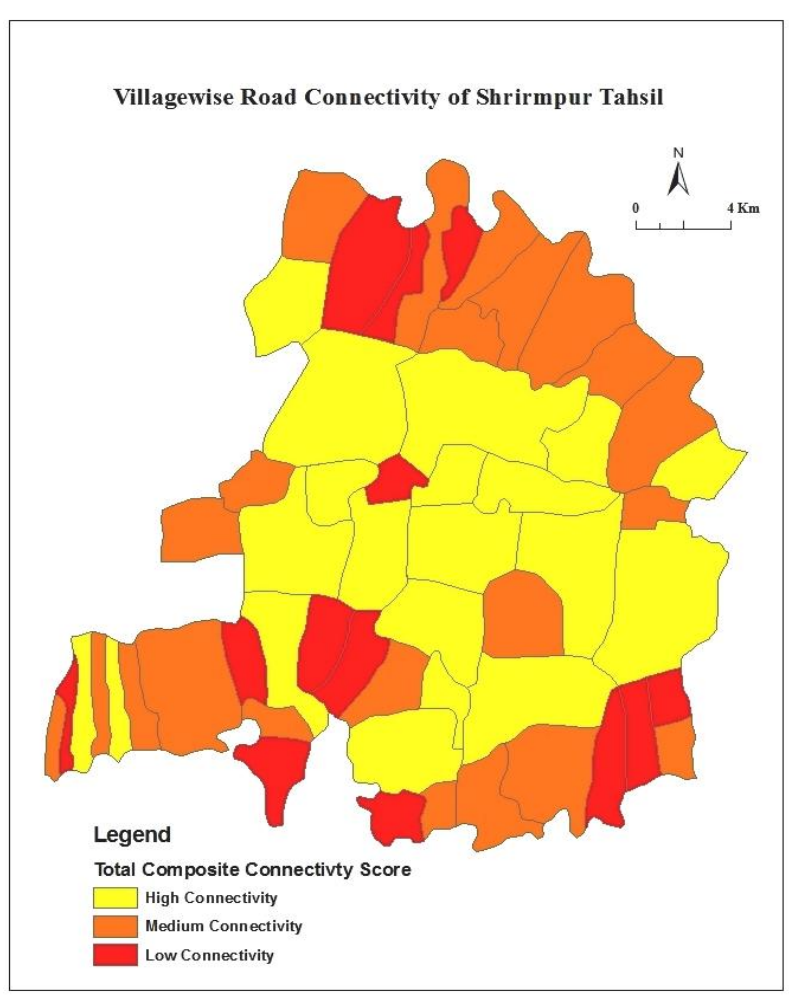

Figure 1: Road Connectivity in Study Area

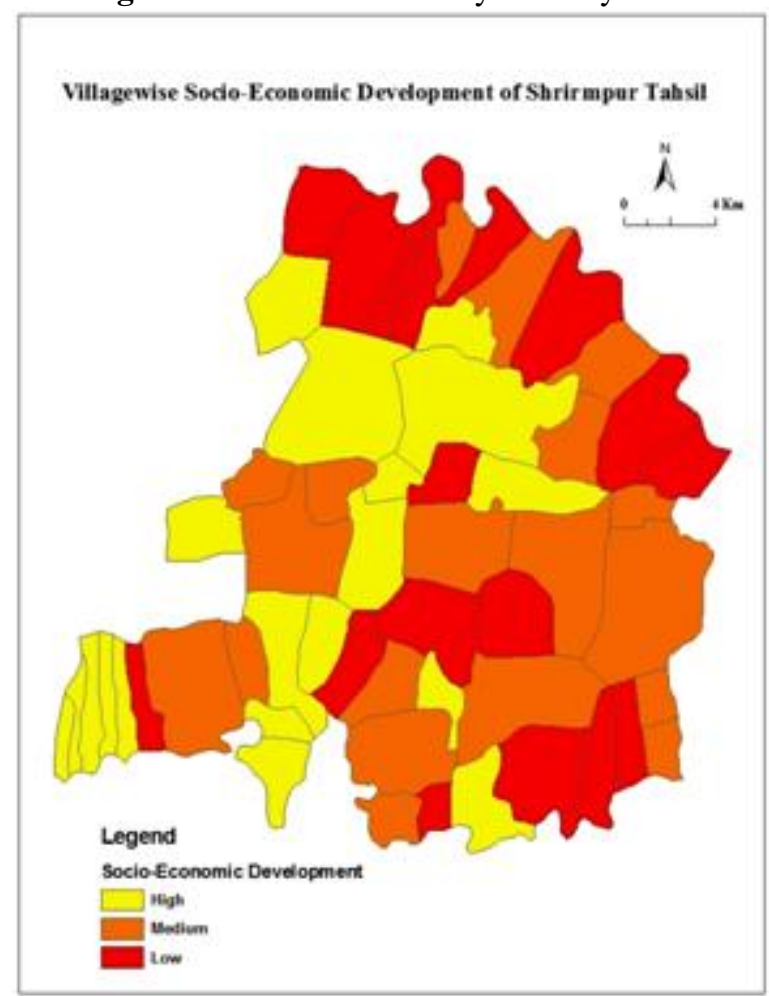

Figure 2: Socio-Economic Development in Study Area

\section{Composite Connectivity Score}

The composite connectivity scores (CCS) have been computed by adding respective ranks of Beta and Cyclomatic number. On the basis of CCS, Shrirampur tahsil has been divided into three categories of high, medium and low connectivity. Here lower the CCS value, higher the connectivity and vice versa. Therefore high connectivity villages are Shrirampur(2), Taklibhan(6), Belapur Bk.(8), Haregaon(10), Padhegaon(15), Shirasgaon(18), Bhokar (21), Nimgaon Khairi(21) while While low connectivity found in the villages, Eklahare(107), Bramhangaon Vetal(95.5), Wangi(106.5), Kanhegaon(95.5), Gurjarwadi(107), Naygaon(107), Jafrabad(89), Ladgaon(78), Rampur(107), because most of the villages are away from the central place (Fig.1).

\section{Socio-Economic Development Composite Score}

In order to facilitate analysis, three categories of high, medium and low economic development have been determined on the basis of composite scores by adding population density, sex ratio, literacy rate, workers of total population $(\%)$ and net sown to total area (\%). Here lower the composite score value, higher the socio-economic development and viceversa. Therefore high socio-economic development villages are Kadit Kh (64), Narsari (81), Kadit bk(92.5), Matapur (97), Muthewadgaon(99.5), Ainatpur, Bramhangaon vetal, Dattanagar, Fatyabad, Gondegaon, Khandala, Kuranpur, Malewadi, Malunje, Mandve, Nimgaon Khairi, Shirasgaon etc. while low socio-econominc development found in the villages, Wangi (237.5), Bhamathan \& Nipaniwadgaon (193), Kamalpur (190.5), Khokar (186.5), Naur (183.5), Matulthan, Naygaon, Jafrabad, Govardhanpur, Mahankalwadgaon etc. and medium connectivity villages including Shrirampur, Dighi, Rampur, Sarala, Khanapur, Ghumandeo, Taklibhan, Bhokar, Wadalamahadev, Karegaon etc. (fig.2).

\section{Correlation Analysis}

The correlation co-efficient has been computed between Road connectivity and socio-economic development on the basis of the Karl Pearson's correlation co-efficient (r) method which is as follows:

$$
\mathbf{r}=\frac{n(\Sigma x y)-(\Sigma x)(\Sigma y)}{\sqrt{\left(n\left(\Sigma x^{2}\right)-(\Sigma x)^{2}\right)}\left(n \times\left(\Sigma y^{2}\right)-(\Sigma y)^{2}\right)}
$$

Where,

$\mathbf{r}=$ is the co-efficient of correlation.

$\mathbf{x}, \mathbf{y}=$ are the two given variables.

$\mathbf{n}=$ is the number of observations.

The rank correlation coefficient between levels of development and degrees of connectivity is 0.11 .

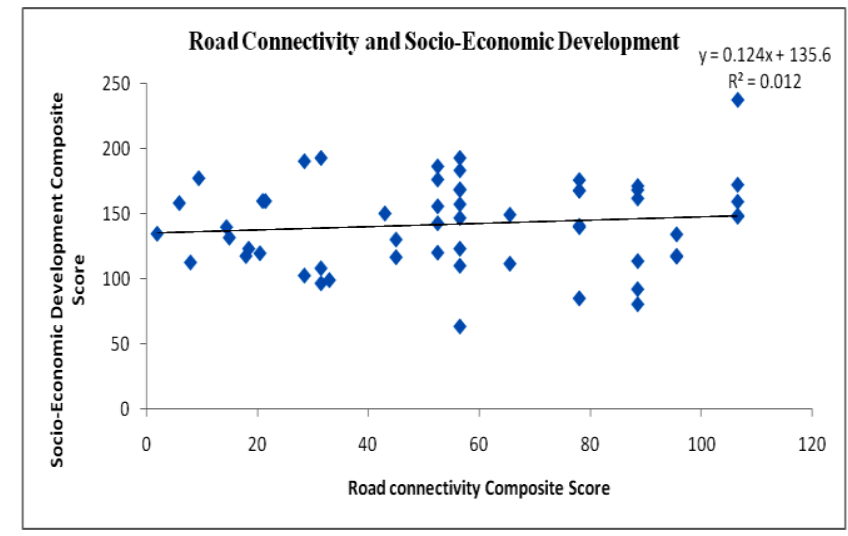

Figure 3: Road Connectivity and Socio-Economic Development in Shrirampur Tahsil 


\section{International Journal of Science and Research (IJSR) \\ ISSN (Online): 2319-7064}

Index Copernicus Value (2013): 6.14 | Impact Factor (2015): 6.391

The Karl Pearson's correlation coefficient (r value) is 0.01 , which is statistically insignificant. This means that the factors governing the development of road connectivity are not related to the factors governing the regional pattern of economic development. Therefore there is very weak correlation between road connectivity and socio-economic development in Shrirampur tahsil (Fig.3).

\section{Conclusions}

Data has been analyzed regarding Road Connectivity and Socio-Economic factors. Composite Connectivity Scores (CCS) has been computed by adding respective ranks of beta and Cyclomatic number. On the basis of CCS, Shrirampur has been divided into three categories of high, medium and low connectivity. Here lower the CCS value, higher the connectivity and vice versa. Therefore high connectivity villages are Shrirampur(2), Taklibhan(6), Belapur Bk.(8), Haregaon(10), Padhegaon(15), Shirasgaon(18), Bhokar (21), Nimgaon Khairi(21) while While low connectivity found in the villages, Eklahare(107), Bramhangaon Vetal(95.5), Wangi(106.5), Kanhegaon(95.5), Gurjarwadi(107), Naygaon(107), Jafrabad(89), Ladgaon(78), Rampur(107), because most of the villages are away from the central place.

In order to facilitate analysis, three categories of high, medium and low Socio-Economic development have been determined on the basis of composite scores. On the basis of Composite Score Here lower the composite score value, higher the socio-economic development and viceversa. Therefore high socio-economic development villages are Kadit Kh (64), Narsari (81), Kadit bk(92.5), Matapur (97), Muthewadgaon(99.5), Ainatpur, Bramhangaon vetal, Dattanagar, Fatyabad, Gondegaon, Khandala, Kuranpur, Malewadi, Malunje, Mandve, Nimgaon Khairi, Shirasgaon etc. while low socio-economin development found in the villages, Wangi (237.5), Bhamathan \& Nipaniwadgaon (193), Kamalpur (190.5), Khokar (186.5), Naur (183.5), Matulthan, Naygaon, Jafrabad, Govardhanpur, Mahankalwadgaon etc. Shrirampur city has been found medium Socio-Economic development.

Correlation between Composite Connectivity Score (CCS) and Socio-Economic Development Score has been analyzed by Karl Person's Correlation method. The Karl Pearson's correlation coefficient ( $\mathrm{r}$ value) is only 0.01 , which is showing very weak correlation between road connectivity and socio-economic development in Shrirampur tahsil.

\section{References}

[1] Saxena, H.M. (1980): 'Road Transport Connectivity Pattern and Economic Development in Rajasthan', Geographical: Review of India, Vol. No.2, pp. 183-87.

[2] Sadhana H. Bhendkar (2011): 'Road Transport Connectivity Pattern and Economic Development in Vidarbha Maharashtra'.

[3] Robinson and Bamford (1978): Geography Of Transport, MacDonald and Evans pub. London pp.80.

[4] Robinson, Roger (1977): Ways to move,. Cambridge University Press, London

[5] Simon, D. (1996): Transport and development in the third world. Routeledge. NY:
[6] Taaffe, Edward,j and Howard L. Gauthier (1973), Geography of transportation pp107, 110-111

[7] Ullman, E.L. (1956, Transportation Geography In American Geography: Inventory And Prospects (Ed) P.E. James and C.L. Jones, Syracuse University press 